\title{
CLIMATE AND THE INITIATION OF MARITIME ICE SHEETS
}

\author{
by \\ Antony Payne* and David Sugden \\ (Department of Geography, University of Edinburgh, Edinburgh EH8 9XP, Scotland, U.K.)
}

\section{ABSTRACT}

The lower latitude extension of polar water during Quaternary glaciations has two opposing effects on the mass balances of adjacent maritime ice sheets. Cooler air temperatures reduce ablation and increase the fraction of precipitation falling as snow, but also lead to reduced atmospheric moisture content and reduced precipitation. The effects of these contrasting processes on ice-sheet initiation are investigated using a coupled ice-sheet-atmospheric moisture model of the Loch Lomond ice sheet in Scotland $(10000$ a B.P. $)$. There is a delicate balance between the degree of cooling required to initiate ice accumulation and that which restricts the flow of moisture over the area. At the regional scale of Scotland, the combined effects of orographic enhancement and the inherent feedback between the rising ice-surface elevation and increasing mass balance are dominant, and ice-sheet growth accelerates. Comparison of the results from models using different wind directions suggests that south-westerly winds were prevalent during the Loch Lomond glaciation in contrast to the dominant westerly winds of the present day. The modelling experiments demonstrate the sensitivity and complexity of the links between ocean surface cooling and ice-sheet growth, particularly at the early stages of a glacial cycle.

\section{INTRODUCTION}

This paper investigates the role of climatic change in initiating the growth of ice sheets. Taking the example of the Loch Lomond glaciation in Scotland (12500 to 9500 a B.P.) a numerical model is used to simulate the response of the Loch Lomond ice sheet to changes in air temperature, precipitation and wind direction.

It is important to study processes of ice-sheet initiation because positive feedback mechanisms can accentuate the effects of a small climatic perturbation and lead to continued ice-sheet growth. In turn this may contribute to the wider global cooling characteristic of an ice age. Ice-sheet growth accelerates up to a certain point because of the relationship between increasing ice surface elevation and increasing rates of ice accumulation, as well as the "albedo chill" effect of increasingly extensive snow surfaces. In the absence of dramatic warming, growth continues until the ice sheet is constrained by continental-scale processes such as latitudinal differences in ablation, atmospheric moisture depletion and marine ice losses. Both the exact nature of a climatic deterioration and the character of the potential ice-sheet seeding area are important in determining whether or not a continental-scale ice sheet is initiated. This paper is concerned with the former topic, while the latter is discussed in Payne and Sugden (in press).

There are three advantages in using the initiation of the Loch Lomond ice sheet as a case study. First, there is a large body of data relating to the climates of both Britain and the North Atlantic Ocean at this time. Two main

* Present address: Water Research Centre, P.O. Box 85 , Frankland Road, Blagrove, Swindon SN5 8YR, England, U.K. sources of data are used in this study; estimates of former British air temperatures based on the ecology of fossil Coleoptera (beetle) assemblages (Coope, 1975) and estimates of former North Atlantic sea-surface temperatures based on the palaeoecology of deep sea sediments (McIntyre and others, 1976). The former data set is used to determine ablation rates over the Loch Lomond ice sheet, while the latter data set is input for an atmospheric moisture conservation model of the North Atlantic, which forms the basis for predicting precipitation patterns over Scotland.

Secondly, the Loch Lomond case study can be used to assess the relative importance of changes in ablation and accumulation in determining overall ice-sheet growth rate. The ablation rate is determined by changing regional air temperatures, while the accumulation rate is determined by the precipitation rates and by North Atlantic atmospheric moisture fluxes. In a maritime location, such as Scotland, falling sea-surface temperatures have two contrasting effects on ice-sheet growth: to increase growth via a reduction in ablation and air temperature, and to reduce growth via a reduction in precipitation and atmospheric moisture. The relative dominance of the two effects is vital in determining the outcome of ice-sheet initiation. An important factor influencing the balance between temperature and precipitation is wind direction. It has been argued that the predominant wind direction in Scotland during the Loch Lomond glaciation was south-westerly, as opposed to the present-day westerly winds (Sissons, 1979). This change may have influenced ice-sheet initiation in that warmer, moister winds may have brought increased precipitation rates to Britain.

Thirdly, the Loch Lomond ice sheet provides well documented field evidence of ice extent and depth, and is accurately dated. Thus model predictions can be tested against a reliable geomorphological record and unlikely scenarios excluded.

\section{THE MODEL}

Rival effects of reductions in air temperature and precipitation rate on the growth of the Loch Lomond ice sheet are analysed by the use of a coupled ice-sheet/ atmospheric moisture model, each component of which is based on a continuity equation.

\section{The ice-sheet model}

The model follows those of Mahaffy (1976) and Budd and Smith (1981), and is based on the continuity equation for ice thickness. Changes in ice thickness are tested through time using the equation

$$
\frac{\mathrm{d} Z}{\mathrm{~d} t}=b-\nabla \cdot\left[Z\left(U_{\mathrm{s}}+U_{\mathrm{d}}\right)\right]
$$

where $Z$ is ice thickness, $t$ is time, $b$ is net mass balance, $U_{\mathrm{d}}$ is vertically averaged deformation velocity and $U_{\mathrm{s}}$ is sliding velocity. The flow section of the model is detailed in Payne and others (1989) and is driven by the balance between basal shear stress and surface slope driving stress. Sliding is found from an empirical relationship between 
basal shear stresses and normal stress on the ice-sheet bed. Equation (1) is approximated over a regular rectangular grid using finite differences and can be used to simulate the time dependent behaviour of the ice sheet.

This paper is mostly concerned with the net massbalance term $(b)$ in Equation (1), which is defined as:

$$
b=P \cdot E f f-A b
$$

where $P$ is the precipitation rate, $A b$ is the ablation rate and $E f f$ is the fraction of annual precipitation falling as snow (effectiveness). Annual precipitation rate provides the link between the ice-sheet model and the atmospheric moisture model and is discussed later

The method used to estimate net mass balance first involves the specification of surface air temperatures. For each year of the model run the annual temperature cycle is approximated using a sinusoidal curve, the amplitude and mean value of which are estimated from latitude, surface elevation and a specified temperature change (Payne, 1988). Monthly air temperatures are obtained from this curve and these are then used to estimate monthly effectiveness and ablation values (Table I). In the former case we use the relationship of Lauscher (1976), which is based on western European data. In the latter case, the monthly air temperature is converted to the monthly sum of day-degrees above $0^{\circ} \mathrm{C}$ and this is then used to calculate the ablation rate. This latter procedure is based on the West Greenland work of Braithwaite and Olesen (1984).

The ice-sheet model requires three sets of input data. The first is bedrock topography, for which a rectangular grid of $5 \mathrm{~km}$ by $5 \mathrm{~km}$ contains the maximum altitude in each grid element (Fig. 1). The second data set consists of similar grids containing annual precipitation rates at the surface of the ice sheet. These are obtained from the output of the atmospheric moisture model at 500 year intervals. The third data set is a time series of regional
TABLE I. THE EQUATION USED TO ESTIMATE MONTHLY EFFECTIVENESS AND ABLATION VALUES (Amp is the amplitude and $O f f$ the offset of the annual air temperature curve (both in ${ }^{\circ} \mathrm{C}$ ). $E$ is the ground elevaiton, $\phi$ latitude and $T$ ije specified regional air temperature changes (obtained from beetle assemblages). $n$ is a "month number" running from 6.5 for July to 1.5 for December. $T_{\mathrm{m}}$ is the monthly gorund surface air temperature; $E f f_{\mathrm{m}}$ the monthly proportion of snow to total precipitation; $S_{\mathrm{m}}$ the monthly sum of day-degrees above $0^{\circ} \mathrm{C}$; and $A b \mathrm{~m}$ the monthly ablation rate in $\mathrm{m} \mathrm{a}^{-1}$ )

$$
\begin{aligned}
& A m p=7.0-1.57 \Delta T_{\mathrm{j}}-0.25(\phi-50.5)-2.0 E \\
& O f f=10.0+2.57 \Delta T_{\mathrm{j}}-0.38(\phi-53.17)-6.5 E \\
& T_{\mathrm{m}}=O f f-A m p \cos \left(\frac{\pi n}{6}\right) \\
& E f f_{\mathrm{m}}=0.50-0.05 T_{\mathrm{m}} \\
& S_{\mathrm{m}}=1.74+0.50 T_{\mathrm{m}}+0.03 T_{\mathrm{m}}^{2} \\
& A b_{\mathrm{m}}=\max \left(0.0,-0.36+0.54 S_{\mathrm{m}}\right)
\end{aligned}
$$

July air temperatures for sea level, which drives the icesheet model. These data are shown in the upper graph of Figure 2 in the form of differences from the present July temperature of $17^{\circ} \mathrm{C}$. These temperature estimates are obtained from the ecology of fossil Coleoptera assemblages (Coope, 1975). They partially determine the modelled values of the ablation rate and the precipitation effectiveness, and are fed directly into the equation modelling the annual temperature cycle.

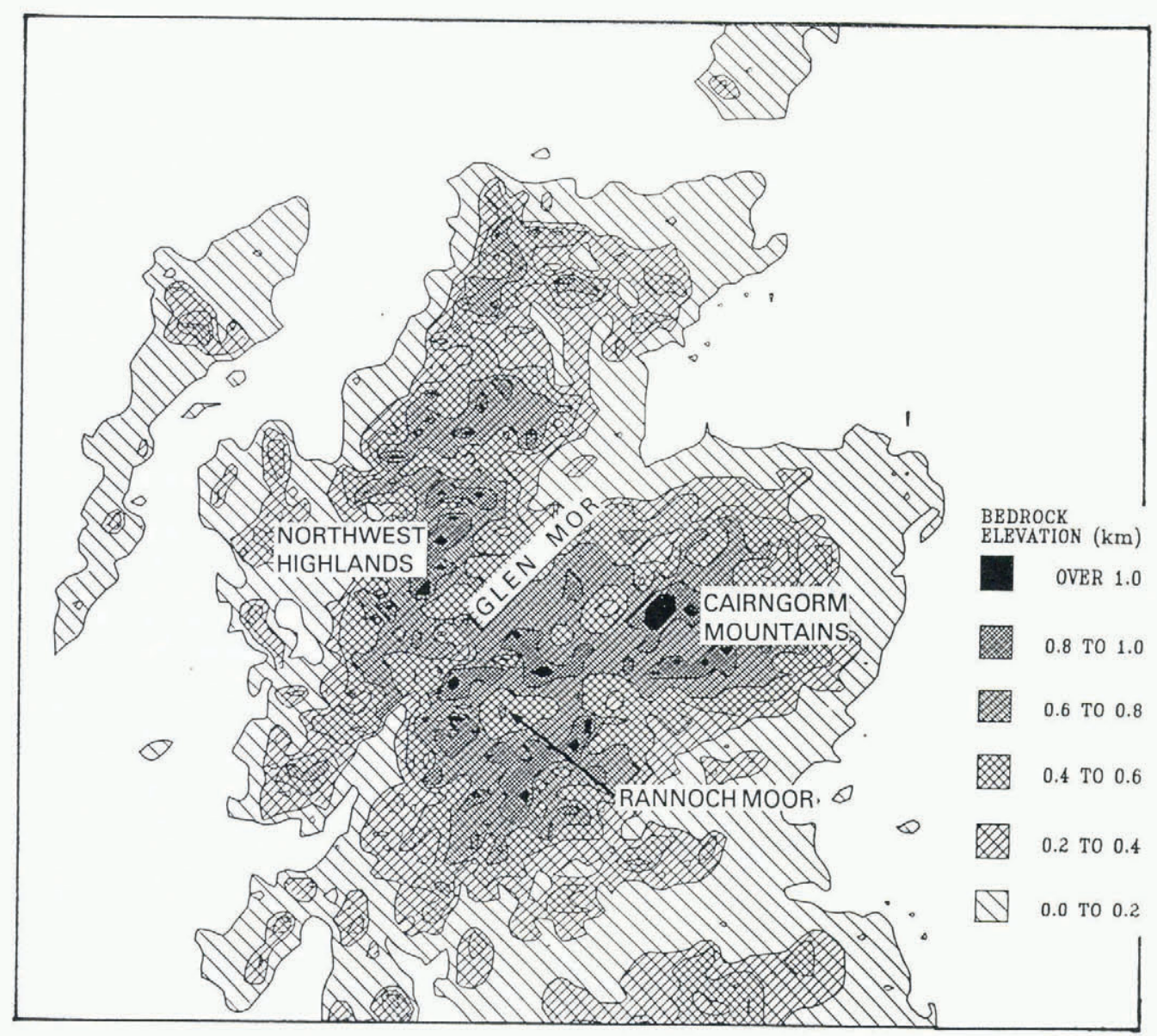

Fig. 1. Contoured representation of Scottish bedrock topography, based on the highest point in each $5 \mathrm{~km}$ by $5 \mathrm{~km}$ grid square. 

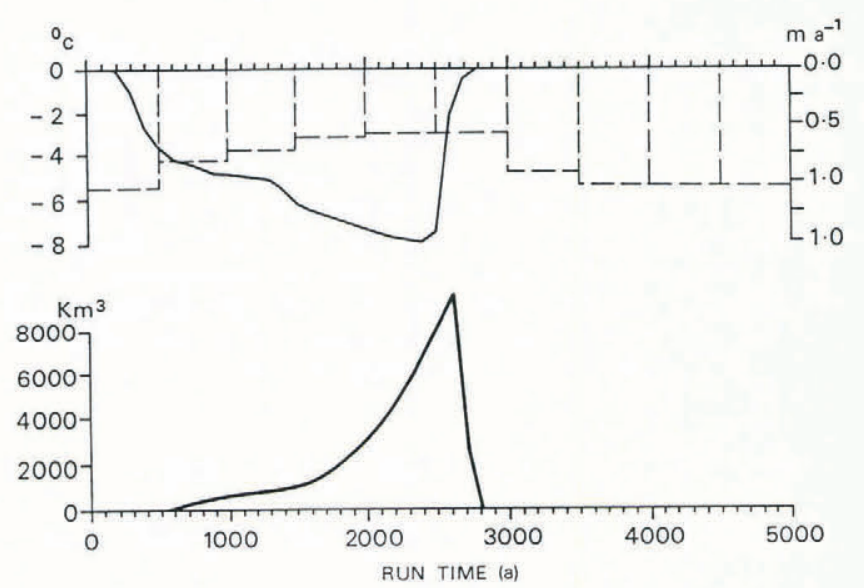

\begin{tabular}{llllll}
12500 & 11500 & 10500 & & 1 & \\
\hline a BP & 9500 & 8500 & 7500
\end{tabular}

Fig. 2. Ice-sheet model input and output. The upper graph shows air temperature and predicted mean precipitation rate; the lower curve shows predicted ice-sheet volume.

The atmospheric moisture model

A separate numerical model is used to assess the effect of falling North Atlantic sea-surface temperatures on the distribution of precipitation over Scotland. The model is based on the vertically integrated continuity equation for atmospheric moisture (Sanberg and Oerlemans, 1983):

$$
\frac{\mathrm{d} W}{\mathrm{~d} t}=\frac{W_{\mathrm{sat}}-W}{T *}-W\left(f_{0}+f_{1} S\right)-U \cdot \nabla W+D_{\mathrm{w}} \nabla^{2} W
$$

where $W$ is the amount of water vapour in a vertical column extending from the ground surface to the "top" of the atmosphere; $W_{\text {sat }}$ is the amount of moisture held in this column when the air is saturated; $T *$ is the time scale over which evaporation occurs; $S$ is the upwind surface slope: $f_{0}$ and $f_{1}$ are empirically derived parameters that determine the relationship between surface slope, atmospheric moisture and precipitation; $U$ is a specified wind velocity field; and $D_{\mathrm{w}}$ is the diffusivity of atmospheric moisture.

The sophistication of the model is intermediate between a purely empirical approach and a full global circulation model. The equation contains terms dealing with evaporation, precipitation, advection and diffusion. The first term in Equation (9) concerns evaporation. The saturated moisture content $\left(W_{\text {sat }}\right)$ is determined from surface elevation at a point and from the equivalent sea-level air temperature at that point. It is the variation of sea-level air temperature which drives the atmospheric moisture model. Precipitation, represented by the second term in Equation (9), is particularly important because it is the link between the atmospheric moisture model and the ice-sheet model. Precipitation responds to changes in both atmospheric moisture and upwind surface slope. Upwind surface slope is specified and provides the basis for introducing the effects of both orographic enhancement and the "precipitation shadow". Predicted precipitation distribution therefore varies in response to the changing topography of the modelled Loch Lomond ice sheet. The third and fourth terms in Equation (9) represent advection and diffusion respectively, and are both concerned with the horizontal movement of moisture through the atmosphere.

The atmospheric moisture model is run at two resolutions. A low-resolution flowline is used to model the flow of atmospheric moisture across the North Atlantic towards Scotland. The horizontal moisture fluxes over Scotland are then fed into the high-resolution twodimensional rectangular grid of the ice-sheet model. In this way, gross North Atlantic moisture fluxes are found quickly using the low-resolution model and the pattern of

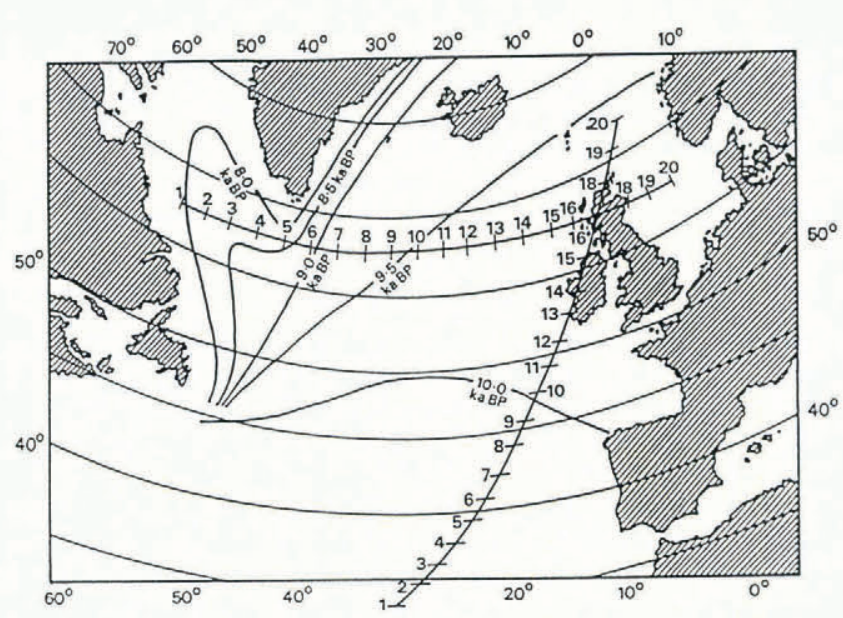

Fig. 3. The transects along which data was collected for the atmospheric moisture model. Also shown are the positions of the North Atlantic polar front $10000-8000$ a B.P. After Ruddiman and McIntyre (1981).

precipitation over Scotland is found in detail using the $5 \mathrm{~km}$ by $5 \mathrm{~km}$ high-resolution model.

The response time of the atmospheric moisture system is considerably shorter than that of the ice-sheet system. The atmospheric moisture model is therefore run to steadystate by iterating Equation 9 forward through time until the volume of atmospheric moisture becomes constant. This process is repeated at regular 500 year intervals using the appropriate North Atlantic sea-surface temperatures to determine the modelled saturation moisture content and Loch Lomond ice-sheet thicknesses to determine the orographic component of precipitation. The final steady-state precipitation distribution is then fed back into the ice-sheet model, which is run forward for a further 500 years. This procedure is used to reduce excessive computation time and yet does not greatly affect the behaviour of the overall model.

The primary input to the North Atlantic flowline component of the model are sea-surface temperature transects across the ocean. These are derived from the maps of Ruddiman and McIntyre (1981) and McIntyre and others (1976) based on the palaeoecology of deep sea sediments. The data set encompasses the migration of the North Atlantic polar front from a position between Newfoundland and Iceland to its maximum southerly extent of $45^{\circ} \mathrm{N} 10000$ years B.P. and its subsequent retreat (Fig. 3). Sea-surface temperatures, which fall to a minimum of $11^{\circ} \mathrm{C}$ below present-day values, are converted to the sea-level air temperatures needed by the model using the regression equation:

$$
T_{\mathrm{a}}=-4.19+1.26 T_{\mathrm{w}}
$$

where $T_{\mathrm{a}}$ is sea-level air temperature and $T_{\mathrm{w}}$ is sea-surface temperature, both in ${ }^{\circ} \mathrm{C}$.

The main inputs to the high resolution Scottish component of the model are the horizontal moisture fluxes from the North Atlantic model and the Scottish topography data used in the ice-sheet model. This latter has two components: the unchanging bedrock topography and the fluctuating form of the modelled ice sheet.

To investigate the effects of changing wind directions during the Loch Lomond stadial two alternative data sets are used to represent westerly and south-westerly airflow conditions. These alternative wind directions have two main consequences in the model. First, the fetch of the airflow alters its geometry relative to the North Atlantic polar front (Fig. 3). Secondly, the distribution of upwind groundsurface slopes obtained from the Scottish topography alters.

\section{RESULTS}

Testing the atmospheric moisture model

The atmospheric moisture model was run to steadystate using present-day North Atlantic sea-level air 

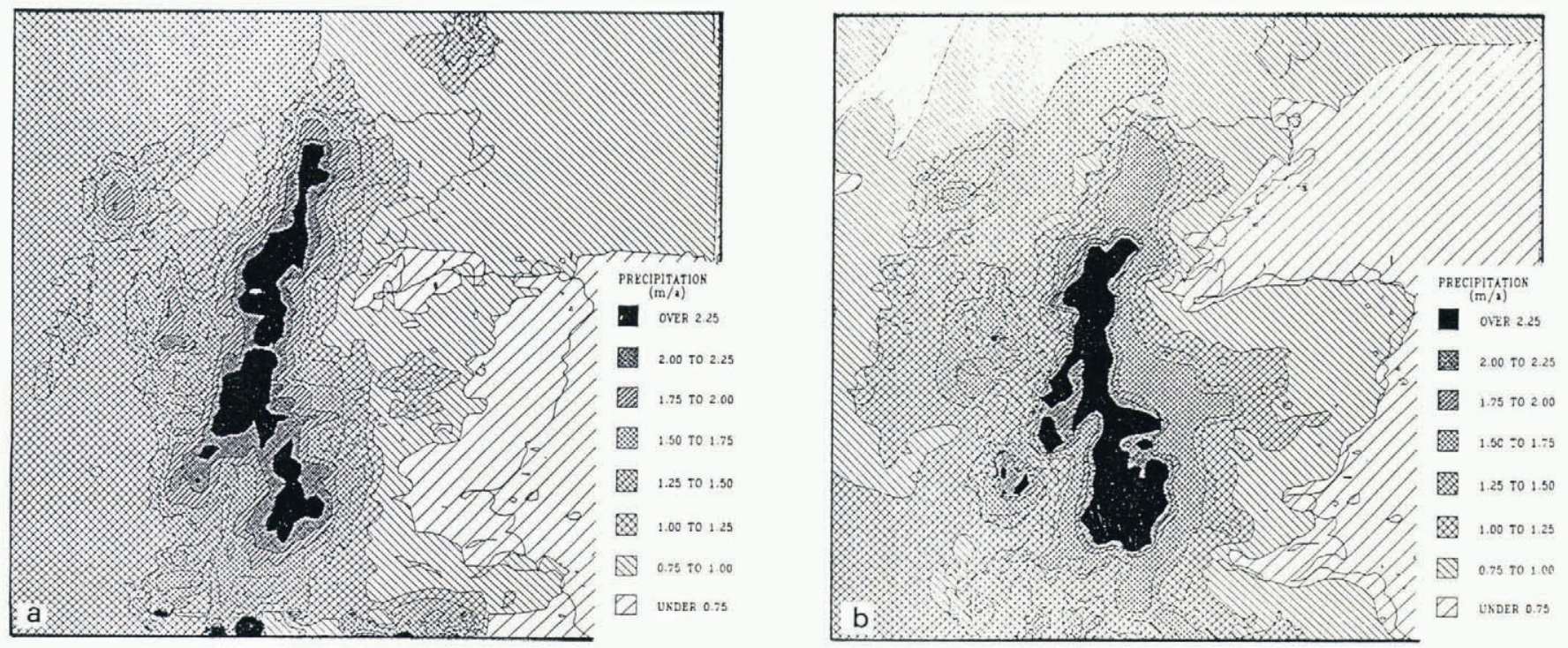

Fig. 4. Contoured representation of (a) present-day precipitation as modelled with a westerly wind direction compared with (b) the actual precipitation pattern.

temperatures and a westerly wind direction. The purpose was to test the reliability of the model. The predicted precipitation distribution is shown in Figure 4. It compares favourably with the actual present-day pattern. Both have peak precipitation rates of $2400 \mathrm{~mm} \mathrm{a}^{-1}$ and typical sealevel values of $750-1000 \mathrm{~mm} \mathrm{a}^{-1}$. The high rates to the west are associated with ground-surface slopes of $0.005-0.007$, while the reduced rates in the east are caused by moisture depletion in the precipitation shadow of the uplands. Atmospheric moisture content $(W)$ in the east is typically one-third of its value in the west. The similarity of predicted and actual patterns gives some credence to the low-resolution flowline model.
The Loch Lomond ice sheet

The coupled model was run for the period $12500-$ 7500 a B.P. using the July air temperature input shown in Figure 2 (upper graph) and a westerly wind direction. Predicted ice-sheet volumes are shown in the lower graph of Figure 2, while the predicted precipitation rates are shown as bars in the upper graph of Figure 2. The predicted precipitation pattern for 10000 a B.P. is shown in Figure 5. Precipitation rates are typically half of their present-day values. However, high rates still occur to the west, where general atmospheric moisture reduction is countered by increased orographic precipitation caused by the elevated Loch Lomond ice-sheet surface.

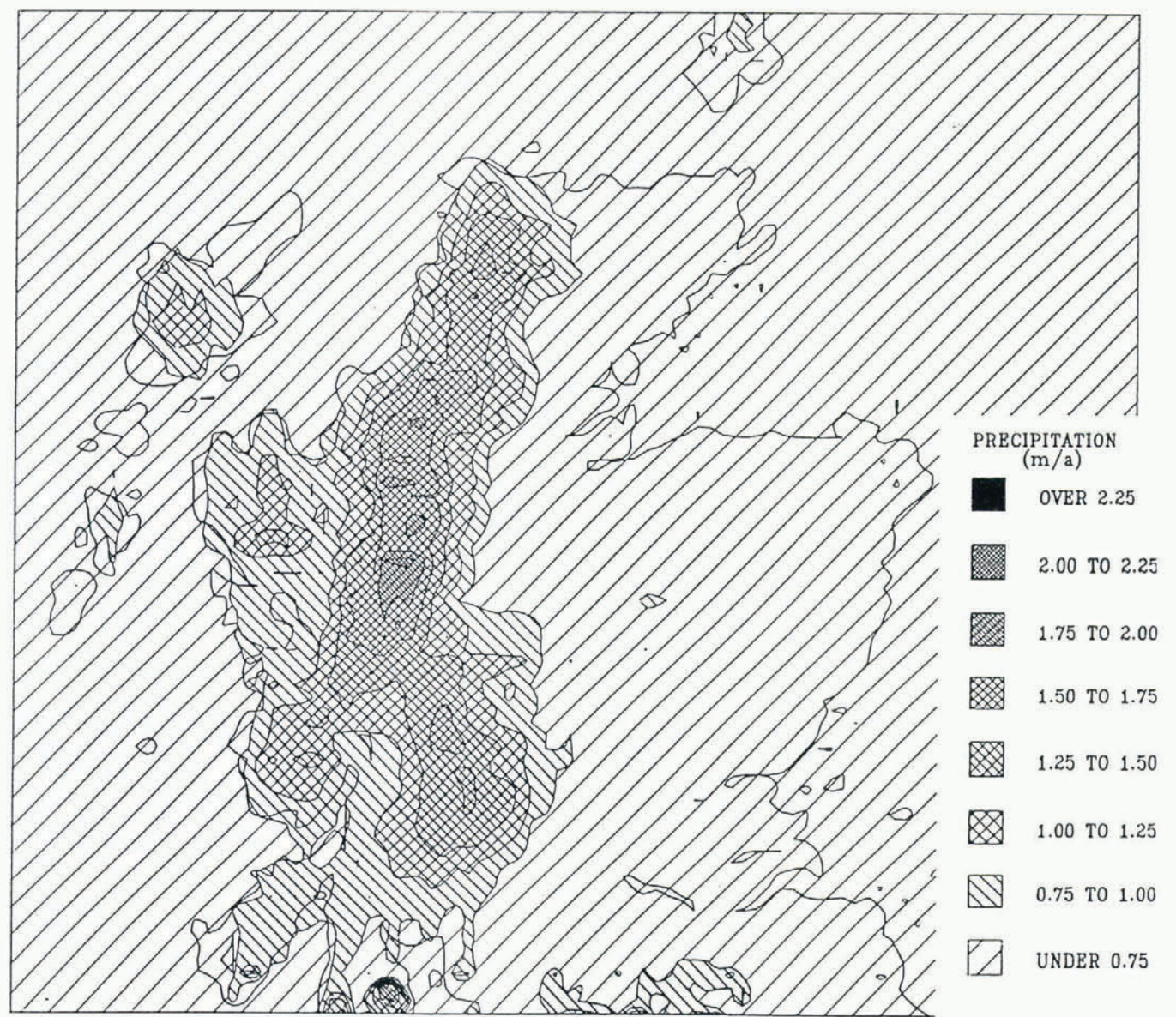

Fig. 5. Contoured representation of precipitation at 10000 a B.P. as modelled with a westerly wind direction. 


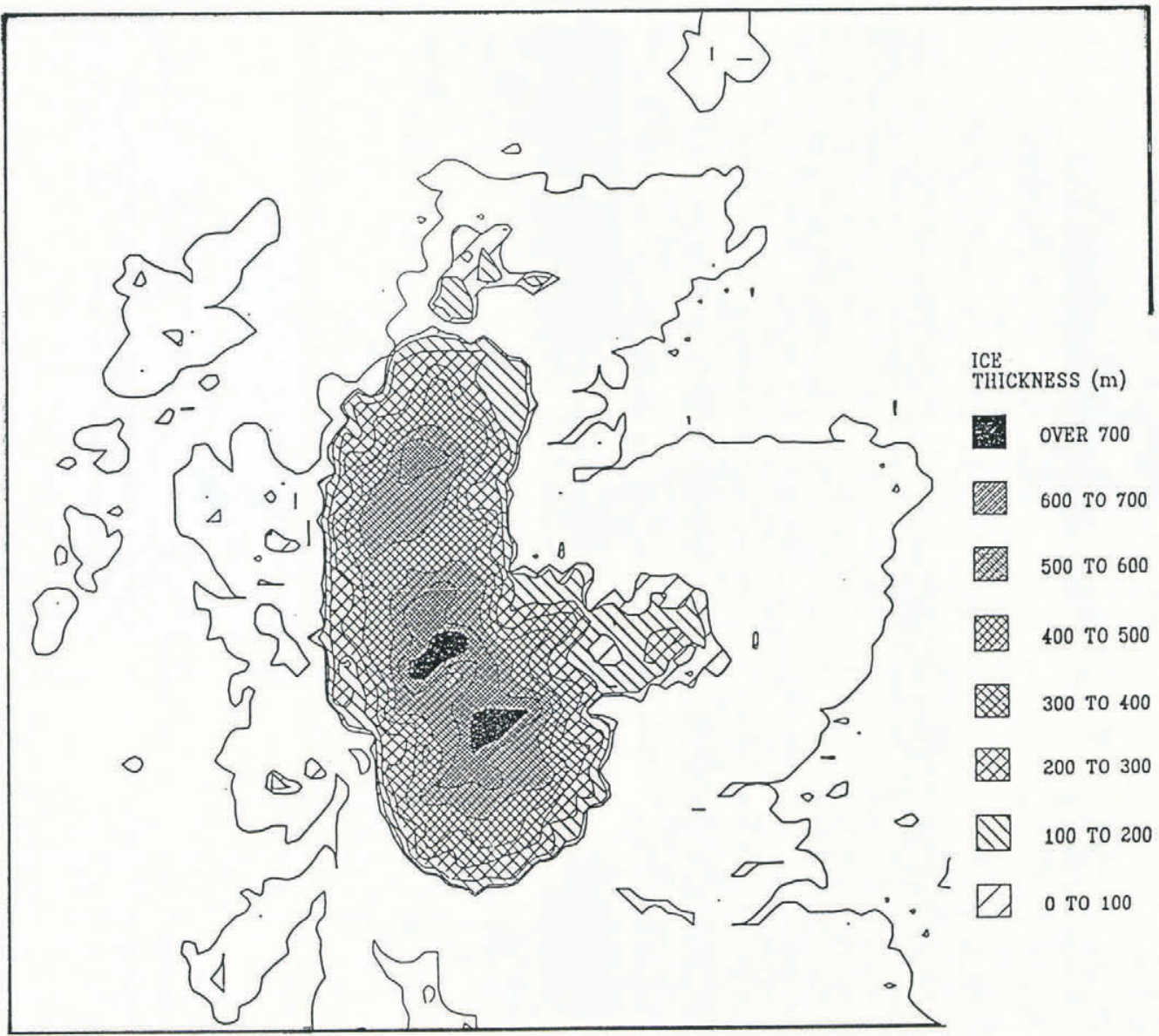

Fig. 6. Predicted ice extent and thickness at the maximum of the Loch Lomond glaciation 10000 a B.P.

The ice sheet reaches a maximum at 10000 a B.P. and its dimensions are shown in Figure 6. The maximum represents a fleeting transition between phases of rapid growth and decay. These rapid changes in volume reflect both changing air temperatures and the positive feedback between ice-surface elevation and net mass balance.

There is generally good agreement between the modelled maximum ice-sheet extent and reconstructions based on geomorphological evidence. The ice sheet builds up in the western Highlands and is centred over the topographic basin of Rannoch Moor. Comparison with fieldbased reconstructions such as that of Sissons (1976) shows that the fit is best in the south and worst in the northwest Highlands, where the model overpredicts the extent of ice.

Alternative wind directions during the Loch Lomond stadial

All of the results described above were obtained using a model incorporating westerly airflow. This section explores the results of model simulations using a south-westerly air flow.

The pattern of precipitation 10000 a B.P. is similar to that for a westerly wind direction (Fig. 5). However, there are two differences. First, precipitation rates are generally higher owing to the increased atmospheric moisture fluxes advected from latitudes south of the North Atlantic polar front (Fig. 3). Secondly, the area of peak precipitation is further south, in the southern Grampians and away from the north-west Highlands and towards the eastern Grampians.

These changes in the precipitation pattern have two effects on the development of the ice sheet. First, the generally higher precipitation rates cause a faster rate of growth and a larger maximum ice sheet. Secondly, the southern Grampians play a more important role in ice-sheet growth.

This latter effect is interesting because it implies that the southern Grampians are more favourable for ice-sheet growth than the north-west Highlands when the airflow is south-westerly. One of the highlighted mismatches between the model using a westerly air flow and geomorphological reconstructions of the Loch Lomond ice-sheet maximum was the overprediction of ice in the north-west Highlands. This mismatch argues in favour of a south-westerly airflow during the Loch Lomond glaciation.

\section{CONCLUSIONS}

(1) The build-up of maritime ice sheets can be triggered by relatively minor climatic perturbations. Once started, continued growth is favoured by the strong relationship between increasing mass balance and increasing ice-surface elevation.

(2) This coupling can be strong enough to overcome the severe precipitation reductions produced by cooling associated with the lower latitude migration of polar ocean water.

(3) In the case of Scotland, the comparison of results from models using different wind directions implies that south-westerly snow-bearing winds were more likely to be prevalent during the Loch Lomond stadial than westerly winds.

\section{ACKNOWLEDGEMENTS}

A.J.P. is indebted to the U.K. Natural Environment Research Council for a research studentship which allowed this work to be carried out. We are both indebted for help and advice to W.F. Budd of the Department of Meteorology, University of Melbourne and to J. Oerlemans of the Institute for Meteorology and Oceanography, University of Utrecht.

\section{REFERENCES}

Braithwaite, R.J. and O.B. Olesen. 1984. Ice ablation in West Greenland in relation to air temperature and global 
radiation. Z. Gletscherkd. Glazialgeol., 20, 155-168.

Budd, W.F. and I.F. Allison. 1975. An empirical scheme for estimating the dynamics of unmeasured glaciers. International Association of Hydrological Sciences Publication 104 (General Assembly of Moscow 1971 - Snow and Ice), 246-256.

Budd, W.F. and I.N. Smith. 1981. The growth and retreat of ice sheets in response to orbital radiation changes. International Association of Hydrological Sciences Publication 131 (Symposium at Canberra 1979 - Sea Level, Ice and Climatic Change), 369-409.

Coope, G.R. 1975. Climatic fluctuations in northwest Europe since the last interglacial, indicated by fossil assemblages of Coleoptera. In Wright, A.E. and F. Moseley, eds. Ice ages: ancient and modern. Liverpool, Seel House Press, 153-168.

Lauscher, F. 1976. Methoden zur Weltklimatologie der Hydrometeore. Der Anteil des festen Niederschlags am Gesamtniederschlag. Arch. Meteorol. Geophys. Bioklimatol., 24, 129-176

McIntyre, A., and 6 others. 1976. Glacial North Atlantic 18,000 years ago: a CLIMAP reconstruction. Geol. Soc.
Am. Mem., 145, 43-76.

Mahaffy, M.W. 1976. A three-dimensional numerical model of ice sheets: tests on the Barnes Ice Cap, Northwest Territories. J. Geophys. Res., 81(6), 1059-1066.

Payne, A.J. Unpublished. Modelling former ice sheets. (Ph.D. thesis, University of Edinburgh, 1988.)

Payne, A.J. and D.E. Sugden. In press. Topography and ice sheet growth. Earth Surface Processes and Landforms.

Payne, A.J., D.E. Sugden, and C.M. Clapperton. 1989. Modeling the growth and decay of the Antarctic Peninsula ice sheet. Quat. Res., 31(2), 119-134.

Ruddiman, W.F. and A. McIntyre. 1981. The mode and mechanism of the last deglaciation: oceanic evidence Quat. Res., 16(2), 125-134.

Sanberg, J.A.M. and J. Oerlemans. 1983. Modelling of Pleistocene European ice sheets: the effect of upslope precipitation. Geol. Mijnbouw, 62(2), 267-273.

Sissons, J.B. 1976. The geomorphology of the British Isles: Scotland. London, Methuen.

Sissons, J.B. 1979. The Loch Lomond stadial in the British Isles. Nature, 280(5719), 199-203. 